\title{
Intervention to Improve Timing of Preoperative Antibiotic Prophylaxis in Major Elective Surgery
}

\author{
Shah JN, ${ }^{1}$ Maharjan SB, ${ }^{1}$ Manandhar K, ${ }^{1}$ Shrestha A, ${ }^{2}$ Piya $R,{ }^{2}$ Basnet NB ${ }^{2}$ \\ ${ }^{1}$ Department of Surgery, ${ }^{2}$ Department of Anesthesia Patan Hospital, Patan Academy of Health Sciences (PAHS), Lalitpur, \\ Kathmandu, Nepal.
}

\begin{abstract}
Aims: Timely administration of antibiotic before incision ensures effective concentration in blood and tissues. Compliance with established guidelines is problematic due to logistics. Aim of this study was to improve timing of antibiotic prophylaxis (AP) with appropriate intervention in existing practices.

Methods: Cross sectional study was conducted from May-June 2011 with target of enrolling at least 100 elective major cases (excluding obstetrics) who received AP before surgery. Anesthetists took responsibility of AP administration (Cefazoline $1 \mathrm{~g}$ as per our protocol unless indicated otherwise) instead of floor nurse as our earlier practice. Institutional ethical committee approved the study. Data collected in a pre-designed proforma was analyzed using Microsoft Excel.

Results: Out of 120 patients, 64\% were female. Average age was 43 years (4 to 87 ). General surgery cases were $51 \%$, urosurgery $20 \%$, gynecology and orthopaedic each $13 \%$ and others $6 \%$. One hundred nineteen $(99 \%)$ received AP before incision, 58(48\%) within 60 to 30 minutes before incision and $1(1 \%)$ after the incision.
\end{abstract}

Conclusions: Anesthetist taking charge of the team for AP administration is a feasible option to improve compliance.

Keywords: Antibiotic prophylaxis, compliance, intervention, surgical site infection, timing.

\section{INTRODUCTION}

Surgical site infection (SSI) is an important contributor of increase in hospital stay, morbidity, mortality and cost. $^{1-3}$ In addition to good aseptic techniques, antibiotic prophylaxis (AP) is an important aid to prevent SSI. ${ }^{4}$

Optimum timing of AP administration within 60 to 30 minutes before incision and not exceeding 2 hours

\section{CORRESPONDENCE}

Prof. Dr. Jay N Shah

Consultant Surgeon, Patan Hospital

Patan Acedemic of Health Sciences

Phone: 9851040139

Email: drjaywufei@hotmail.com before surgery ${ }^{5-8}$ is most effective in preventing SSIs. ${ }^{9-}$ ${ }^{16}$ Our earlier study ${ }^{17}$ and literatures ${ }^{14,18-21}$ reveal poor compliance to established guidelines. Study conducted at our institute revealed that $19 \%(24 / 125)$ got AP after the incision. ${ }^{17}$ Korean study from six referral hospitals found that only $11.2 \%(188 / 1,676)$ patients received prophylaxis within optimum time before surgery. ${ }^{22}$ Multicenter study in Netherlands reported only $28 \%$ of patients met AP guidelines. ${ }^{23}$ Similarly in a Canadian study only $5 \%$ AP complied with protocol. ${ }^{24}$ 
Scenario may be similar in Nepal as there is lack of published data on adherence to guidelines. After discussion among the team of 'surgeons- operating room (OR) nurses-anesthetists' we planned to introduce changes in our existing practices to improve compliance of AP timing. In this study, we did not aim to study efficacy of drugs or SSIs because no amount of 'good' antibiotic will achieve the goal if it is not given on time before incision. In present study we concentrated on 'intervention' to improve compliance to established guidelines on 'timing of AP' administration.

\section{METHODS}

This cross sectional study was conducted (from May 15 to June 15,2011 ) with target of enrolling at least 100 cases of elective major cases that were scheduled to receive AP before surgery as per our existing institutional practice. Our practice has been to give Cefazoline $1 \mathrm{gm}$ intravenous before surgery in all major cases unless indicated otherwise. The exception for example is Gentamycin in urosurgery cases.

We discussed among 'surgeon-OR nurse-anaesthetists' to introduce changes to optimize the timing of AP. The changes in practice in this study included anesthetist taking overall charge of AP administration instead of floor nurses in OR which has been the practice at our institute. Traditional practice at our institute has been anesthetists to put intravenous (IV) line after the patient is being kept on operation table and floor nurses administer AP. We discussed with nurses and anesthetist to modify this practice. In present study, the anesthetists took responsibility to oversee that AP was given within optimum time of within 60-30 minutes before incision. Patients were received by OR nurse as peroperation list which is distributed at least one day before surgery. Anesthetists put IV line in the waiting area looking at the operation schedule as well as ongoing operations (we run 3 4 OR simultaneously) to give AP (with help of nurses) so that AP timing could be optimized within 60 to 30 minutes before incision. Re-dosing of antibiotic was given after four hours when surgery was extended for longer duration.

An 'AP form' was designed with date, time of AP administration, type of surgery and incision time. Forms were kept in each operation room. Members of anesthetic team were requested to fill in the forms. One member of surgical team was designated to collect the forms and enter data in predesigned Microsoft Excel data sheet for analysis.

Ethical approval was obtained from institutional review committee. All the elective major surgery cases scheduled to receive AP as per our institutional practice were included in the study. The emergency surgeries, and the patient with known allergy to antibiotic were excluded. Microsoft Excel was used to analyze data.

\section{RESULTS}

There were 120 cases who received AP as per our protocol during study period from May 15 to June 15, 2011. Females were $64 \%$. Average age was 43 years (4 to 87 ). General surgical cases, mainly gastrointestinal and biliary diseases accounted for 51\% (61/120) and Gynecology and Urosurgery cases each were 13\% (Figure 1). Overall, 99\% got AP before incision, $48 \%$ within 60 to 30 minutes of incision. One patient had AP after the incision (Table 1). Two cases, one for 'pancreaticoduodenectomy' (seven hours) and another 'total gastrectomy' (5 hours) received repeat dose of antibiotic.

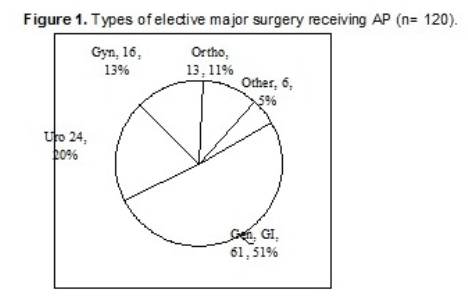

Note: AP- antibiotic prophylaxis, Uro- urosurgery, Gyn- gynecology, Ortho- orthopedic, Gen-
general, GI- gastrointestinal

\begin{tabular}{lllll}
$\begin{array}{l}\text { Timing of } \\
\text { AP } \\
\text { (Minute) }\end{array}$ & $\mathrm{N}$ & $\%$ & $\mathrm{~N}$ & $\%$ \\
\cline { 2 - 4 } & & & & \\
\hline $\begin{array}{l}\text { Before } \\
\text { incision }\end{array}$ & 119 & 99 & 101 & 81 \\
$<5$ & 7 & 6 & 64 & 51 \\
$6-15$ & 11 & 23 & 25 & 20 \\
$16-30$ & 42 & 35 & 11 & 9 \\
$31-60$ & 58 & 48 & 1 & 1 \\
$>60$ & 1 & 1 & & \\
After inci- & 1 & 1 & 24 & 19 \\
sion & & 1 & 11 & 9 \\
$<5$ & 1 & & 7 & 5 \\
$6-15$ & & & 6 & 5 \\
$>15$ & & & &
\end{tabular}

Note: AP- antibiotic prophylaxis

\section{DISCUSSION}

After introduction of intervention in existing practice we observed improved compliance in AP administration, 99\% of patients receiving antibiotic before the incision. Studies have shown that two thirds of SSIs can be prevented ${ }^{25-27}$ by timely and appropriate administration 
of AP. ${ }^{25,28-30}$ However, compliance with the established guidelines is often far from optimal as found in our earlier study ${ }^{17}$ and reported literatures. ${ }^{14,18-21}$ Awareness, lack of co-ordination and resistance to accept changes are some of the barriers to successful implementation of evidencebased practice of AP. To overcome these issues, we had discussions among 'surgeons-OR nurses-anesthetist' to introduce changes to improve the timing of AP administration before incision in major elective surgeries at our institute. Collaborative approach with appropriate intervention is important to improve compliance with standard protocol. $^{31}$ Besides strict aseptic procedures, timely administration of AP before incision to achieve adequate concentration of drugs at tissue level is important to control colonization of surgical wound and prevention of $\mathrm{SSIs}^{20}$ Based on timing, AP may be 'early' (2-24 hours before incision), 'preoperative' (within 2 hours before the incision), 'peri-operative' ( 3 hours after the incision) and 'postoperative' (3-24 hours after the incision)..$^{12}$

Even though we had improved result after intervention in present study, there is space to do more to better comply with the established guidelines for AP. In present study among $99 \%$ of patients who got AP before incision only $48 \%$ were within $60-30$ before incision. (Table 1 ). This demands further consolidation of team effort and communication among 'surgeon-nurse-anesthetist'. Failure in system to implement guidelines leads to increased SSIs, morbidity, mortality, and increased health care costs. Both institute and individual health care provider have obligation to safeguard rights of the patient. Clearly defined role, high priority and better communication can improve compliance to guidelines. The web based guidelines from CDC (Centers for Disease Control and Prevention), APIC (Association for Professionals in Infection Control and Epidemiology) and SHEA (Society for Healthcare Epidemiology of America) are some of the useful resources on issues related to AP and SSIs. ${ }^{12}$

Introduction of appropriate changes with anesthesia department assuming responsibility in present study was successful in reducing number of patients receiving AP after incision like in other study. ${ }^{32}$ Our findings support the view that increasing awareness to evidence based practice can improve compliance and quality. Study from university hospitals in USA found improved compliance from $56 \%$ to $84 \% .^{33}$ Interventions based on specific circumstances of institute and its services are key issues to improve compliance. ${ }^{34}$ Issues which influence compliance to guidelines include: i) Individualknowledge, attitudes, beliefs and practice; ii) Team workcommunication and allocation of responsibilities; iii) institution policy- support for promoting and monitoring practice. ${ }^{35}$ The implementation of SURgical PAtient Safety System (SURPASS) checklist was useful in improving time of AP before incision. ${ }^{36}$ Awareness and periodical audit helps ensure proper use of AP. ${ }^{37,38}$ In present study we introduced changes to optimize AP administration. In initiation of surgeons, the anesthetist took charge of timing of AP administration with the help of OR nurses. This resulted in 99\% (119/120) of AP before incision (from earlier $81 \%{ }^{17}$ ). Also, the number of patients increased to $48 \%$ (from earlier $1 \%{ }^{17}$ ) who got AP within optimum time of 60 to 30 minutes before incision. Less than $1 \%(1 / 120)$ received AP after the incision (from earlier $19 \%{ }^{17}$ ).

The anesthetist plays crucial role in maintaining the safe recovery of patients in peri-operative period. This study supports our belief that anesthetists are the best member of the team (surgeon-OR nurse-anesthetist) to ensure timely administration of AP in OR before incision.

The new knowledge added by this study- Existing practice of AP at institution level needs improvement through periodical audit. Appropriate intervention is needed to comply with the established evidence based protocols and guidelines to ensure AP administration within 60 to 30 minutes before incision. For this compliance, anesthetist is probably the best member of the team (of surgeon-OR nurse-anesthetist) in OR environment.

Possible implications- The result of this study is useful in clinical practice, system development at institution level and evaluation of existing practices of AP. Team work among all the stake holders (surgeon-OR nurseanesthetist) with anesthetist leading the responsibility of AP administration can improve the compliance of AP within 60 to 30 minutes before incision. Periodical audit of the institutional protocol is important to evaluate the practice and devise appropriate intervention.

\section{CONCLUSIONS}

Introduction of changes in practice resulted in improvement in timing in accordance with the standard protocol of antibiotic prophylaxis before incision in elective major surgeries.

\section{ACKNOWLEDGMENTS}

We would like to thank anesthetic team and OR nurses for their supports in introducing changes in practice of antibiotic prophylaxis. 


\section{REFERENCES}

1. Kasatpibal N, Thongpiyapoom S, Narong MN, Suwalak N, Jamulitrat S. Extra charge and extra length of postoperative stay attributable to surgical site infection in six selected operations. J Med Assoc Thai. 2005;88(8):1083-91.

2. Kirkland KB, Briggs JP, Trivette SL, Wilkinson WE, Sexton DJ. The impact of surgical-site infections in the 1990s: attributable mortality, excess length of hospitalization, and extra costs. Infect Control Hosp Epidemiol. 1999;20(11):725-30.

3. Wong ES. The price of a surgical-site infection: more than just excess length of stay. Infect Control Hosp Epidemiol. 1999;20(11):722-4.

4. Davey P, Malek M, Thomas P. Measuring the cost-effectiveness of antibiotic prophylaxis in surgery. Am J Surg. 1992;164:39S-43S.

5. Bratzler DW, Houck PM. Antimicrobial prophylaxis for surgery: an advisory statement from the National Surgical Infection Prevention Project. Clin Infect Dis. 2004;38(12):1706-15.

6. Morita K, Smith KM. Antimicrobial prophylaxis in orthopedic surgery. Orthopedics. 2005;28(8):749-51.

7. Bratzler DW, Houck PM. Antimicrobial prophylaxis for surgery: an advisory statement from the National Surgical Infection Prevention Project. Am J Surg. 2005;189(4):395-404.

8. Antimicrobial prophylaxis for surgery. Treat Guidel Med Lett. 2004;2(20):27-32.

9. Whitehouse JD, Friedman ND, Kirkland KB, Richardson WJ, Sexton DJ. The impact of surgical-site infections following orthopedic surgery at a community hospital and a university hospital: adverse quality of life, excess length of stay, and extra cost. Infect Control Hosp Epidemiol. 2002;23(4):183-9.

10. Coello R, Charlett A, Wilson J, Ward V, Pearson A, Borriello P. Adverse impact of surgical site infections in English hospitals. J Hosp Infect. 2005;60(2):93-103.

11. Perencevich EN, Sands KE, Cosgrove SE, Guadagnoli E, Meara $E$, Platt R. Health and economic impact of surgical site infections diagnosed after hospital discharge. Emerg Infect Dis. 2003;9(2):196-203

12. Classen DC, Evans RS, Pestotnik SL, Horn SD, Menlove RL, Burke JP. The timing of prophylactic administration of antibiotics and the risk of surgical-wound infection. N Engl J Med. 1992;326:281-6.

13. Bratzler DW, Houck PM. Antimicrobial prophylaxis for surgery: an advisory statement from the National Surgical Infection Prevention Project. Am J Surg. 2005;189(4):395-404.

14. Mangram AJ, Horan TC, Pearson ML, et al. Guideline for prevention of surgical site infection, 1999. Hospital Infection Control Practices Advisory Committee. Infect Control Hosp Epidemiol. 1999;20(4):250-78.

15. Weber WP, Marti WR, Zwahlen M, Misteli H, Rosenthal R, Reck S, etal. The timing of surgical antimicrobial prophylaxis. Ann of Surg. 2008;247(6):918-26.

16. van Kasteren ME, Mannien J, Ott A, Kullberg BJ, de Boer AS Gyssens IC. Infections following total hip arthroplasty: timely administration is the most important factor. Clinical Infectious Diseases. 2007;44(7):921-7.

17. Shah JN, Maharjan SB, Manadhar K. Need of Improvement in Timing of Prophylactic Antibiotic in Elective Surgery. Asian Journa of Medical Sciences. 2011;2(3):207-11.

18. Gilbert DN, Moellering RC, Sande MA. The Sanford Guide to Antimicrobial Therapy, 2003. 33rd ed. Hyde Park, Vt: Antimicrobial Therapy Inc. 2003:123-4.

19. Silver A, Eichorn A, Kral J, et al. Timeliness and use of antibiotic prophylaxis in selected inpatient surgical procedures. Am J Surg. 1996;171(6):548-52.

20. Gorecki P, Schein M, Rucinski JC, Wise L. Antibiotic administration in patients undergoing common surgical procedures in a community teaching hospital: the chaos continues. World J Surg. 1999;23:429-33.
21. Burke JP. Maximizing appropriate antibiotic prophylaxis for surgical patients: an update from LDS Hospital, Salt Lake City. Clin Infect Dis. 2001;33(Suppl 2):S78-S83

22. Infection Control and Hospital Epidemiology. 2007;28(8):997-1002.

23. vanKasteren MEE, Kullberg BJ, deBoer AS, et al. Adherence to local hospital guidelines for surgical antimicrobial prophylaxis: a multicentre audit in Dutch hospitals. J Antimicrob Chemother 2003;51(6):1389-96.

24. Wasey N, Baughan J, deGara CJ. Prophylaxis in elective colorectal surgery: the cost of ignoring the evidence. Can J Surg. 2003;46(4):279-84.

25. Mangram AJ, Horan TC, Pearson ML, et al. Guideline for prevention of surgical site infection, 1999. Centers for Disease Control and Prevention (CDC) Hospital Infection Control Practices Advisory Committee. Am J Infect Control. 1999;27(2):97-132.

26. Page $C P$, Bohnen JM, Fletcher JR, et al. Antimicrobial prophylaxis for surgical wounds. Guidelines for clinical care. Arch Surg. 1993;128(4):79-88

27. Platt R, Munoz A, Stella J, et al. Antibiotic prophylaxis for cardiovascular surgery. Efficacy with coronary artery bypass. Ann Intern Med. 1984;101(6):770-4.

28. Chodak GW, Plaut ME. Use of systemic antibiotics for prophylaxis in surgery: a critical review. Arch Surg. 1977;112(3):326-34.

29. Horan TC, Gaynes RP, Martone WJ, et al. CDC definitions of nosocomial surgical site infections, 1992: a modification of CDC definitions of surgical wound infections. Infect Control Hosp Epidemiol. 1992;13(10):606-8.

30. Kurz A, Sessler DI, Lenhardt R. Perioperative normothermia to reduce the incidence of surgical-wound infection and shorten hospitalization. Study of Wound Infection and Temperature Group. N Engl J Med. 1996;334:1209-15.

31. Forbes SS, Stephen WJ, Harper WL, Loeb M, Smith R, Christoffersen EP, McLean RF. Implementation of evidence-based practices for surgical site infection prophylaxis: results of a pre- and postintervention study. J Am Coll Surg. 2008;207:336-41.

32. O'Reilly M, Talsma A, VanRiper S, Kheterpal S, Burney R. An anesthesia information system designed to provide physicianspecific feedback improves timely administration of prophylactic antibiotics. Anesth Analg. 2006;103:908-12.

33. Kao LS, Lew DF, Doyle PD, Carrick MM, Jordan VS, Thomas EJ, Lally KP. A tale of 2 hospitals: A staggered cohort study of targeted interventions to improve compliance with antibiotic prophylaxis guidelinesSurgery 2010;148:255-62.

34. Meeks DW, Lally KP, Carrick MM, Lew DF, Thomas EJ, Doyle PD, Kao LS. Compliance with guidelines to prevent surgical site infections: As simple as 1-2-3? The American Journal of Surgery. 2011;201:76-83.

35. Gagliardi AR, Fenech D, Eskicioglu C, Nathens AB, McLeod R. Factors influencing antibiotic prophylaxis for surgical site infection prevention in general surgery: a review of the literature. Can J Surg. 2009;52(6):481-9.

36. De Vries EN, Dijkstra L, Smorenburg SM, Meijer RP, Boermeester MA. The surgical patient safety system (SURPASS) checklist optimizes timing of antibiotic prophylaxis. Patient Safety in Surgery. 2010;4:6.

37. Pan SC, Sun HY, Lin JW, Lin C, Lai TS, Chang SC. Improvement in timing of antibiotic administration by using a prophylactic antibiotic record form. J Formos Med Assoc. 2008;107(3):218-24.

38. Thonse R, Sreenivas M, Sherman KP. Timing of antibiotic prophylaxis in surgery for adult hip fracture. Ann R Coll Surg Engl. 2004;86:2636. 